Acknowledgments: This work was supported by PARTNER fellowship. Disclosure of Interests: None declared DOI: 10.1136/annrheumdis-2020-eular.4749

\section{THU0525 DIAGNOSTIC PERFORMANCE OF MAGNETIC RESONANCE IMAGING FOR DETECTING SUBCHONDRAL BONE EROSION OF SACROILIAC JOINTS IN PATIENTS WITH SUSPECTED SPONDYLOARTHRITIS}

D. Ben Nessib ${ }^{1}$, H. Riahi ${ }^{2}$, H. Ferjani ${ }^{1}$, E. Labbene ${ }^{2}$, D. Kaffel ${ }^{1}$, M. Bouaziz ${ }^{2}$, M. M. Kchir ${ }^{1}$, F. Ladeb ${ }^{2}$, W. Hamdi ${ }^{1} .{ }^{1}$ Kassab Institute of Orthopedics, Rheumatology, Mannouba, Tunisia; ${ }^{2}$ Kassab Institute of Orthopedics, Radiology, Mannouba, Tunisia

Background: The utility of structural lesions of sacroiliac joints (SIJ) for the early diagnosis of spondyloarthritis (SpA) has been well established by previous reports [1]. Computed tomography (CT) is usually the preferred modality to assess structural changes.

Objectives: The aim of this study was to evaluate the performance of magnetic resonance imaging (MRI) for detecting subchondral bone erosions of SIJ in patients with suspected SpA. SIJ CT findings were considered as the gold standard when interpreting results.

Methods: A cross-sectional prospective monocentric study included consecutive patients aged over 16 and consulting for symptoms suggestive of SpA from February 2014 to February 2017. Patients with a confirmed sacroiliitis on pelvic radiograph were not included. Eligible patients underwent CT and MRI of SIJ. Imaging findings were assessed consensually by 2 experimented musculoskeletal radiologists, blinded to the clinical and laboratory data. Erosion was defined as resorption or destruction of the subchondral bone. The sensitivity, specificity, positive and negative predictive values of MRI for detecting SIJ erosions were determined with CT results as gold standard.

Results: Fifty-four patients were enrolled: 13 men and 41 women. The average age at inclusion was $39.4 \pm 11$ years [17-59], and the average age at onset of symptoms was $35.6 \pm 10.6$ years [16-55]. Cervical, thoracic, lumbar and buttock pain were noted respectively in $46.3 \%, 37 \%, 92.6 \%$, and $57.4 \%$ of the studied patients. Sacroiliac compression test, distraction provocative test, sacral thrust test, Gaenslen's test, Faber's test (Patrick) and Mennel's test were respectively positive in $23,18,24,12,28$, and 17 patients. HLA B27 typing was positive in $23.4 \%$ of patients. Erosions were detected by CT scan in 30 patients. MRI showed erosions in 18 of them. A significant association was found between CT and MRI results $(p=0.000)$, and between the presence of erosions and the diagnosis of $\operatorname{SpA}(p=0.05$ for $C T$ and $p=0.012$ for $M R I)$. Sensitivity, specificity, positive and negative predictive values of MRI for detecting subchondral erosions were respectively estimated at $60 \%, 100 \%, 100 \%$ and $66.7 \%$.

Conclusion: Erosions of SIJ appear in early stages of SpA and have been reported in $60-90 \%$ of patients with axial SpA after mean symptom duration of 2.5 years[2, 3], hence the importance of the detection of these structural lesions. In our study, despite its moderate sensitivity, MRI showed an excellent specificity for detecting subchondral bone erosions.

References:

[1] Weber U, Lambert RGW, Pedersen SJ, et al (2010) Assessment of structural lesions in sacroiliac joints enhances diagnostic utility of magnetic resonance imaging in early spondylarthritis. Arthritis Care Res 62:1763-1771. https:// doi.org/10.1002/acr.20312

[2] Althoff CE, Sieper J, Song I-H, et al (2013) Active inflammation and structural change in early active axial spondyloarthritis as detected by whole-body MRI. Ann Rheum Dis 72:967-973. https://doi.org/10.1136/ annrheumdis-2012-201545

[3] Weber U, Lambert RGW, Østergaard M, et al (2010) The diagnostic utility of magnetic resonance imaging in spondylarthritis: an international multicenter evaluation of one hundred eighty-seven subjects. ArthritisRheum 62:30483058. https://doi.org/10.1002/art.27571

Disclosure of Interests: None declared

DOI: 10.1136/annrheumdis-2020-eular.5076

\section{THU0526 1 MEASUREMENT OF RADIOLOGICAL JOINT WIDTH IS THE KEY IN ASSESSING HIP INVOLVEMENT OF HIPS IN ANKYLOSING SPONDYLITIS.}

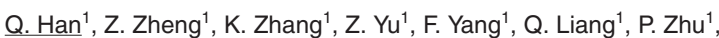
X. Baraliakos ${ }^{2} .{ }^{1}$ Department of Clinical Immunology, PLA Specialized Research Institute of Rheumatology \& Immunology, Xijing Hospital, Fourth Military Medical University, Xi'an, China; ${ }^{2}$ Rheumazentrum Ruhrgebiet Herne, RuhrUniversity Bochum, Herne, Germany
Background: Hip involvement is one of the most disabling complications of ankylosing spondylitis (AS). Frequently, arthroplasty is necessary by the time symptoms appear.

Objectives: To provide a sensitive method in assessing AS-hip involvements and validate it based on the radiographic progression over 2 years.

Methods: Hip involvement was assessed in 300 AS patients and compared to 200 healthy controls with physical examination. Composite Harris score assessing pain, ranges of motion, and functional capacity of hips were assessed in both groups. Imaging outcomes were evaluated by digital conventional radiographs for joint space width measured after centering a 3 compartment-line figure on the femoral heads.

Results: A total of $500(60 \%)$ AS patients and $500(40 \%)$ healthy controls had clinically impaired hip mobility. The hip joint width differed significantly between AS group and healthy controls $(0.93 \pm 0.54$, range $5.41-0.35 \mathrm{vs}$ $4.83 \pm 0.74$, range $6.72-3.56, P<0.0001)$. Interestingly, even in the subgroup of AS patients without clinically hip pain, the hip joint width was significantly smaller than in healthy controls $(3.29 \pm 0.66$, range $5.4-2.1$ vs $4.83 \pm 0.74$, range 6.72-3.56, $\mathrm{P}<0.0001)$. We then evaluated the MRI images of the same 300 subjects. First, we evaluated the 200 control subjects to establish a threshold. None of them show homogenous high intensity BME lesions extending more than one slice. we examine the MRI of the 300 AS patients. Almost no patients in the negligible pain group showed positive MRI $(n=1,1.2 \%)$. Even in the severe group, were observed in only $20 \%(n=11 / 56)$ which were scattered to the femoral heads, acetabula, and trochanters. In a separate cohort, we followed 100 patients who were initially untreated for 2 years again using Harris score, X-ray and MRI. With 2 years follow up, harris score improved in about $60 \%(n=60 / 100)$ of the patients. Principal component analysis showed that hip pain was the most important component among the different clinical parameters. Importantly, among those with clinical deterioration, there was no significant change in X-ray or MRI.

Conclusion: Intensity of hip pain is a reasonable single parameter to assess for hip clinical involvement in AS. The higher the hip pain, the narrower the hip joint width. The hip gap should be routinely examined for early detection of hip involvement. Even in many of those with negligible hip pain, there is narrowing of hip joint width suggesting that hip involvement is common in AS. Hip disease progresses very slowly over 2 years.

References:

[1] KIRSTEN MACKAY, CHRISTOPHER MACK, SINEAD BKOPHY.et al. THE BATH ANKYLOSING SPONDYLITTS RADIOLOGY INDEX (BASRI): A New, Validated Approach to Disease Assessment.[J] ARTHRITIS \& RHEUMATISM. 1998(41), pp 2263-2270.

[2] MacKay K, Brophy S, Mack C, Doran M, Calin A.The development and validation of a radiographic grading system for the hip in ankylosing spondylitis: the bath ankylosing spondylitis radiology hip index. [J] J Rheumatol. 2000 Dec;27(12):2866-72.

[3] Julie C, Baker-LePain, Nancy E. Lane.Relationship between joint shape and the development of osteoarthritis. Curr Opin Rheumatol. [J] 2010; 22(5): 538-543.

[4] Zhen Guo, Huang, Xue Zhe, Zhang, Wen Hong. et al. The application of MR imaging in the detection of hip involvement in patients with ankylosing spondylitis.[J] European journal of radiology. 2013;82(9):1487-1493.

[5] M. Konsta \& P. P. Sfikakis \& V. K. Bournia.et al. Absence of radiographic progression of hip arthritis during infliximab treatment for ankylosing spondylitis. [J] Clin Rheumatol 2013; (32):1229-1232

[6] Hyemin Jeong, Yeong Hee Eun, In Young Kim.et al. Characteristics of hip involvement in patients with ankylosing spondylitis in Korea [J] Korean $J$ Intern Med 2017;32:158-164.

\begin{tabular}{|c|c|c|c|c|c|c|c|c|c|c|c|c|}
\hline AS group & $\mathrm{ABO}^{\circ}$ & Sex & $\begin{array}{l}\text { Duraton } \\
\text { (M) }\end{array}$ & $\begin{array}{l}\text { Harris } \\
\text { scoser }\end{array}$ & BASDAI & BASFI & BASMa & $\mathrm{PO}$ & $\begin{array}{l}\text { CRP } \\
\text { modd }\end{array}$ & $\begin{array}{l}\text { ESR } \\
\text { MMMH }\end{array}$ & HLA.B27 & joint wittlemum) \\
\hline Nurber & 300 & 300 & 300 & 300 & 300 & 300 & 300 & 300 & 265 & 279 & 287 & 300 \\
\hline Medius & 27 & 1 & 48 & $n$ & 58 & 36 & 1 & 8 & 127 & 22 & 1 & 1.73 \\
\hline Mean & 2994 & 0.74 & 6738 & $n_{82}$ & $5 \theta \theta$ & 37.48 & 126 & 802 & 238 & 23.10 & 0.92 & 193 \\
\hline 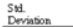 & 1032 & 0.44 & 6539 & 884 & 158 & 18.78 & 198 & 125 & 498 & 1953 & 027 & 0.94 \\
\hline
\end{tabular}

Table2 Health control characteristics

\begin{tabular}{lcccc}
\hline Health control & Age & Sex & harris score & joint width(mm) \\
\hline Number of values & 200 & 200 & 200 & 200 \\
Median & 27.00 & 1.00 & 100.00 & 4.76 \\
Mean & 29.94 & 0.74 & 94.90 & 4.85 \\
Std. Deviation & 10.45 & 0.44 & 6.59 & 0.74 \\
\hline
\end{tabular}

